\title{
LA VIOLACIÓN DE LOS DERECHOS DE LAS MUJERES ANTE EL DELITO DE TRATA DE PERSONA
}

\author{
C. Soledad García Robles ${ }^{1}$ \\ Dr. José Antonio Morales Notario ${ }^{2}$
}

Resumen: La trata de personas afecta y daña directamente a las mujeres de diferentes edades entre 5 a 30 años de edad aproximadamente. Es un fenómeno que se ha destacado desde hace mucho tiempo nacional e internacionalmente. Este delito se realiza con engaños; es decir que el consentimiento en ningún momento se dio, sí en dado caso lo fue, pierde el valor automáticamente porque está viciado. Al realizar la captura o secuestro de las mujeres, son expuestas a cumplir con trabajos forzados y sexuales. Por ejemplo: las obligan a trabajar en bares, table dances, burdeles entre otros lugares con la misma similitud; también las obligan a pedir limosna, las prostituyen, hacen pornografía infantil a las niñas que son de 5 a 12 años y las mujeres mayores pornografía de adultos entre 17 a 30 años. Estos son algunos de los delitos que les hacen a multitudes de mujeres que son obligadas a realizar bajo amenazas, golpes, y torturas. Existe la posibilidad de confundir la trata y el tráfico de personas por ello se mencionan ambas definiciones y sus características para evitar la confusión. Desde luego se hará una breve referencia de su marco normativo nacional e internacional para señalar que tanto protegen a las mujeres al privar de su libertad y derechos dejándolas vulnerables en un escenario en que nadie puede ayudarlas en ese momento que se comete el delito, es decir que las mujeres se encuentran en un grito silencioso, debido a toda la violencia que se comete en el delito de trata de persona.

Palabras Claves: Trata de personas, violencia, vulnerabilidad

\begin{abstract}
Trafficking affects and directly damages women of different ages between 5 and 30 years of age. It is a phenomenon that has long stood out nationally and
\end{abstract}

\footnotetext{
${ }^{1}$ Estudiante en Lic. en Derecho de la Universidad Juárez Autónoma de Tabasco.

${ }^{2}$ Doctor en Derecho y Profesor Investigador de la Universidad Juárez Autónoma de Tabasco.
} 


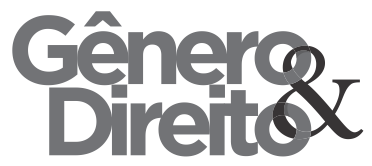

internationally. This crime is done with deceit; that is to say that the consent in no moment was given, if in any case it was, it loses the value automatically because it is vitiated. When they capture or abduct women, they are exposed to forced and sexual labor. For example: they force them to work in bars, table dances, brothels among other places with the same similarity; They also force them to beg, prostitute, make child pornography for girls who are from 5 to 12 years old, and older women pornography for adults between 17 and 30 years. These are some of the crimes they do to multitudes of women who are forced to perform under threats, beatings, and torture. There is a possibility of confusing trafficking and trafficking in persons, so both definitions and their characteristics are mentioned to avoid confusion. Of course, a brief reference will be made to their national and international normative framework to point out that they both protect women by depriving them of their freedom and rights, leaving them vulnerable in a scenario where no one can help them at the time the crime is committed; that is to say, that women are in a silent cry because of all the
Códico do Núcleo de Estudos e Pesquisas sobre Gênero e Direito Centro de Ciências Jurídicas - Universidade Federal da Paraíba V. 6 - No 03 - Ano 2017 (Spanish Edition) 126

violence that is committed in the human trafficking.

Keywords: Human Trafficking, violence, vulnerability

\section{INTRODUCCIÓN}

La trata de personas ha tenido una evolución a través de la época, antes conocida y denominada trata de blancas, las mujeres que se encontraban en riesgo eran las europeas y americanas debido a que el objetivo era realizar solo explotación sexual, ahora no sólo existe la explotación sexual sino que destaca otros abusos que se ven forzadas a sufrir (Comisión Nacional de los Derechos Humanos [CNDH], (2012).

Cada año las personas que son víctimas de la trata de personas son cerca de 4.000.000, la mayoría son mujeres y niñas, entre el $10 \%$ y el $30 \%$ de mujeres son menores de edad. Según la Organización Internacional del Trabajo (OIT), más de 12.3 millones de personas son obligadas a labores similares de esclavitud. Estimativamente la trata mueve 12 millones de dólares por año sólo en América latina. 2 millones de niñas y 


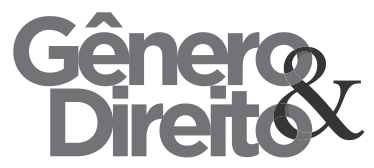

adolescentes son víctimas de explotación sexual comercial y laboral (Fondo de las Naciones Unidas para la Infancia [UNICEF], (2007).

La trata de personas es la captura de mujeres, adolescentes y niñas cuya violación directa es la privación de su libertad, y posteriormente la explotación de las víctimas con trabajos forzosos y sexuales; este es un delito que aún sigue siendo situado nacional e internacionalmente.

Son principalmente las mujeres las que sufren de este delito violentando sus derechos y dejándolas vulnerables. Mujeres que son encontradas de diferentes estatus social, edad, nivel educativo, lugar de origen, entre otras. Por ellos es necesario conocer e identificar el marco normativo nacional e internacional que proteja a la mujer de la trata de personas.

\section{TRATA Y TRAFICO DE PERSONAS, SU CONCEPTO Y DIFERENCIA.}

La trata de personas es la captura, rapto o secuestro de niñas, adolescentes y mujeres mediante engaños, o sea sin el consentimiento de la persona. En dado caso que lo hubiese consentido
Codico do Núcleo de Estudos e Pesquisas sobre Gênero e Direito Centro de Ciências Jurídicas - Universidade Federal da Paraíba V. 6 - No 03 - Ano 2017 (Spanish Edition)

automáticamente pierde su valor por el hecho de estar viciada. Al cometer este delito las privan de la libertad quedando vulnerables de sus derechos para después poder explotarlas por medio de trabajos forzados y sexuales. No podemos dejar pasar que la esclavitud es parte de este delito, claro además de la pérdida de su libertad y dignidad, son sometidas a condiciones de vida infrahumanas ([UNICEF], (2007).

En el caso de La ley para prevenir y sancionar la trata de personas el artículo $5^{\circ}$ lo identifica como:

"Comete el delito de trata de personas quien promueva, solicite, ofrezca, facilite, consiga, traslade, entregue o reciba, para sí o para un tercero, a una persona, por medio de la violencia física o moral, engaño o el abuso de poder para someterla a explotación sexual, trabajos o servicios forzados, esclavitud o prácticas análogas a la esclavitud, servidumbre, o a la extirpación de un órgano, tejido o sus componentes" (Cámara de Diputados del H. Congreso de la Unión, (2012).

El tráfico de persona es el traslado de un lugar de origen a otro, es decir que la persona entra de manera ilegal a un Estado sin haber cumplido los 
requisitos para ello, esto para obtener directa o indirectamente una finalidad de un beneficio financiero $\mathrm{u}$ otros. Debido a que las personas sufren de carencias principalmente económicas (Oficina de las Naciones Unidas contra la Droga y el Delito [UNODC], (2009).

Tráfico ilícito de migrantes lo define el Protocolo Contra el Tráfico Ilícito de Migrantes por Tierra, Mar y Aire en su artículo $3^{\circ}$ :

"Por "tráfico ilícito de
migrantes" se entenderá la
facilitación de la entrada ilegal
de una persona en un Estado
Parte del cual dicha persona no
sea nacional o residente
permanente con el fin de
obtener, directa o
indirectamente, un beneficio
financiero u otro beneficio de
orden material" (Naciones
Unidas [ONU], (1999).

Se entiende entonces que la trata de personas es la captura de personas que al ser privados de su libertad y vulnerar sus derechos, esta se realiza con engaños o abusos de poder, con el fin de explotarlas en trabajos forzados y sexuales de tal manera tener múltiples ganancias de ello, mientras que el tráfico de personas es el cruce irregular a la frontera, es decir al movimiento ilícito de migrantes de un lugar de origen a otro; esto es con el consentimiento de la persona que le otorga al contacto directo que es llamado pollero, él se encarga de trasladar a las personas advirtiendo del peligro que pueden tener como de ser atrapados por migración, también cabe la posibilidad de perder la vida, entre otros peligros.

Existen características que diferencian estas dos figuras:

Consentimiento: En la trata de personas no existe el consentimiento, en dado caso si hubiera, el consentimiento será de forma viciada por lo tanto pierde su valor; en cambio en el tráfico de personas existe el consentimiento desde el inicio y fin del acuerdo entre el migrante y pollero o coyote ([UNODC], (s.f.).

Transnacionalidad: En la trata de personas el lugar puede o no variar, es decir que no es necesario cruzar la frontera, en el tráfico de personas si hay que pasar los límites territoriales ([UNODC], (s.f.).

Fin: La trata de personas tiene como objetivo el explotar a las personas con trabajos forzados y sexuales e ilícitos, para obtener múltiples ganancias de ello; con referencia al tráfico de personas solo existe una negociación entre un supuesto 


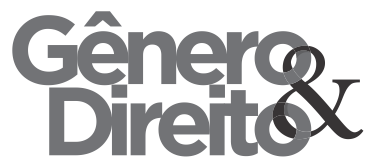

migrante y el pollero, negociación que consiste en la llegada al lugar acordado; al llegar al lugar en ese momento se termina el trato o acuerdo (Comisión Nacional de los Derechos Humanos [CNDH], (2012).

\section{CARACTERÍSTICAS DE LAS VÍCTIMAS DE TRATA DE PERSONAS}

Usualmente las características de las víctimas son variadas, es decir, no tienen un estereotipo fijo y eso dificultad que las autoridades puedan tener o hacer una amplia investigación a los casos que se han suscitado en el país. Uno de los primeros puntos a resaltar es la edad, pues define qué tipo de delito se realizara sobre la persona. Si son niñas o menores de 12 años existe la posibilidad de que les realicen extracción de órganos, pornografía infantil, puedan ser vendidas con fines de explotación sexual, o para pedir limosna en la calle. En cambio a las adolescentes las obligan a hacer trabajos forzados y sexuales, venden su virginidad al mejor postor o cliente, la hacen trabajar en burdeles o bares; las mujeres en promedio de 25 años en adelante las prostituyen, realizan pornografía y dico do Núcleo de Estudos e Pesquisas sobre Gênero e Direito Centro de Ciências Jurídicas - Universidade Federal da Paraíba V. 6 - No 03 - Ano 2017 (Spanish Edition)

trabajos forzados y sexuales. Son diversos los delitos que están a la vista, sin embargo esto son los más concurrentes que se ejecutan en la trata de personas.

No existe un estatus educativo directamente, los que efectúan estos delitos se inclinan por la ignorancia de la personas, es decir que si no tiene un nivel educativo para ellos es mejor, para poder manipularlas, convencerlas y amenazar a las personas que les harán daño cuando no hagan lo que les piden, así como diciendo que harán daño a sus familiares.

La trata de personas no se trata de un secuestro exprés en que solamente adquieran una cantidad de dinero y dejen ir a la persona a su hogar de vuelta; es el ingreso que obtendrán con las pactos ilícitos, sin importar que la persona tenga un estatus social superior o bajo.

El estado donde es más concurrente este delito es en la Ciudad de México, colocando a Puebla en el segundo lugar de trata de personas; lugares en que las autoridades han podido rescatar a varias víctimas con éxito. Esto no quiere decir que la trata de personas deje de ser un peligro para la mujer, ya que de los casos que se tienen conocimiento, sólo el $10 \%$ o $20 \%$ son rescatadas, delito que 


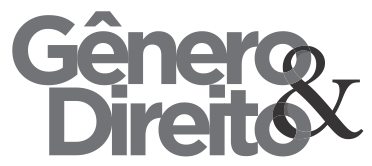

resulta en una terrible crueldad y es inhumano para todas aquellas mujeres que la sufren. (Tirzo, 2014)

Ahora bien, luego de secuestrar, raptar o capturar a la víctima, el lugar al que son llevadas después de ese proceso, debe tener las siguientes características: ser cerrados, solitarios y poco habitados, tipo bodegas o casas que parecen abandonadas por los dueños, o también cabe la posibilidad de que las lleven a lugares donde las pondrán a trabajar de manera obligada como burdeles, bares, table dances, entre otro lugares con estas similitudes.

Una de las formas de engaño que utilizan es hacer que la adolecente se enamore y días después las invitan a un viaje; viaje del que luego no regresan a sus hogares. Otra manera de engaño es decirle que las convertirán en modelos o artistas y que tienen que hacer una sesión de fotos para conseguirles trabajo, o bien, secuestran, capturan o raptan a las niñas, adolescentes y mujeres, en lugares solitarios, calles poco frecuentadas, incluso de su mismo hogar si es que son vigiladas. Los riesgos que puede tener la mujer son derivados de la vulnerabilidad en que se encuentran en ese momento, es ahí donde operan los que realizan este delito y se aprovechan de ella.

Uno de los factores en que una mujer puede caer en las garras de esos delincuentes es por la necesidad y crisis por la que el país mexicano está pasando y si no tiene un nivel educativo superior no es fácil encontrar un trabajo, o bien la posibilidad de que tengan familiares en el extranjero o también el querer tener un mejor equilibrio personal y económico.

Por eso los delincuentes que se dedican a este tipo de delitos saben que movimientos hacer para llegar a su objetivo que es obtener mujeres, pactan un acuerdo con un traficante o pollero y les entrega las mujeres para que las envíen a donde solicitan. En el momento que llegan al lugar destinado todo tiene un cambio radical, es decir, las personas no seguirán su camino y se convierten en víctimas de tratante de personas, por lo que se ven expuestas a diversos actos delictivos de los que pocas veces pueden escapar o pedir ayuda.

\section{MARCO}

NORMATIVO

INTERNACIONAL DE COMBATE A LA TRATA DE PERSONAS 


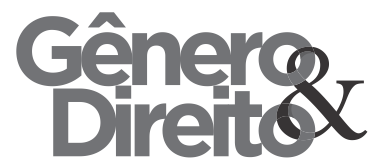

De acuerdo a la legislación Internacional y en específico a la Ley $\mathrm{N}^{\circ}$ 137-03 sobre tráfico ilícito de migrantes y trata de personas de la República Dominicana, sabe que la trata y el tráfico de personas cada vez aumentan más, rompiendo incluso los límites geográficos, más aún cuando son encaminados en contra de la mujer buscando hacerles daño.

La Constitución Dominicana prohíbe este delito en su artículo 41 rezando así: “se prohíben en todas sus formas, la esclavitud, servidumbre, la trata y el tráfico de personas." Según datos de la Organización Internacional para las Migraciones, cada año unos 2 millones de personas son víctimas de la trata de personas, de las cuales el $80 \%$ son mujeres y niñas, y el $20 \%$ son personas menores de edad. Los migrantes son vulnerables al convertirse en mercancía, y esto en algunos casos, por buscar una mejor calidad de vida en el extranjero sin miedo a los peligros que pueden enfrentar (Ivelissec2, 2014).

Dentro de la Convención Americana sobre Derechos Humanos "Pacto de San José de Costa Rica" se protege los derechos humanos de toda persona desde el momento de su ódico do Núcleo de Estudos e Pesquisas sobre Gênero e Direito Centro de Ciências Jurídicas - Universidade Federal da Paraíba V. 6 - No 03 - Ano 2017 (Spanish Edition) concepción; es decir, en el momento en que nace un bebe tiene derechos. La explicación radica en que la persona adquiere obligaciones solamente a partir de los 18 años, o bien, con la emancipación. Pero los derechos si se obtienen por el simple hecho de ser humano. Recordemos que los derechos humanos son derecho a la vida, integridad personal, derecho a la libertad, seguridad personal, ser escuchado, derecho del niño, igualdad ante la ley, protección judicial y otros. Todos estos derechos están protegidos por esta convención y que enfatiza el verificar que respeten nuestros derechos y no los rebasen y dañen desde nuestra integridad personal, al igual que nuestro derecho a la vida, salud, educación entre otros derechos y que la convención protege a toda costa (Organización de los Estados Americanos [OEA], (1969).

En la Convención Interamericana para prevenir, sancionar y erradicar la Violencia contra la Mujer "Convención de Belén Do Pará”, se establece y protege el derecho de la mujer a vivir una vida libre de violencia o cualquier maltrato que la dañe o la perjudique.

“...constituye una violación de los derechos humanos y las libertades fundamentales $\mathrm{y}$ 


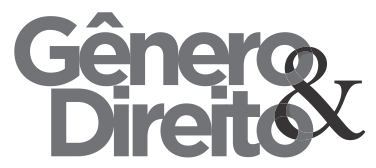

limita total o parcialmente a la mujer el reconocimiento, goce y ejercicio de tales derechos y libertades"

“...es una ofensa a la dignidad humana y una manifestación de las relaciones de poder históricamente desiguales entre mujeres y hombres" "...trasciende todos los sectores de la sociedad independientemente de su clase, raza o grupo étnico, nivel de ingresos, cultura, nivel educacional, edad o religión y afecta negativamente sus propias bases" "Para los efectos de esta Convención debe entenderse por violencia contra la mujer cualquier acción o conducta, basada en su género, que cause muerte, daño o sufrimiento físico, sexual o psicológico a la mujer, tanto en el ámbito público como en el privado" ([OEA], 1994).

Esto se debe a la vulnerabilidad en que se encuentran, y por lo mismo, también las protege de otros delitos. La convención hace mención de delitos como la discriminación, respeto a la vida, la integridad física, psíquica y moral, el derecho a no ser sometida a la tortura, entre otras. Por ello esta convención prevé la sanción, erradicación y sanción de esos delitos que violentan a la mujer. Son tres
Cíco do Núcleo de Estudos e Pesquisas sobre Gênero e Direito Centro de Ciências Jurídicas - Universidade Federal da Paraíba V. 6 - No 03 - Ano 2017 (Spanish Edition)

132

tipos de violencia que se reconocen que es violencia física, psicológica y sexual, los cuales se pueden realizar en la vida privada o pública.

\section{MARCO NORMATIVO NACIONAL DE COMBATE A LA TRATA DE PERSONAS}

La Ley general para prevenir, sancionar y erradicar los delitos en materia de trata de personas y para la protección y asistencia a las víctimas de estos delitos

La ley es reglamentaria del artículo 73, fracción XXI, párrafo primero, en materia de trata de personas, de la Constitución Política de los Estados Unidos Mexicanos. Tiene por objeto establecer competencias y formas de coordinación para la prevención, investigación, persecución y sanción de los delitos en materia de trata de personas entre los Gobiernos Federal, Estatales, del Distrito Federal y Municipales y por consiguiente establecer los tipos penales en materia de trata de personas y sus sanciones; también determinar los procedimientos penales aplicables a estos delitos y la distribución de competencias y formas de coordinación en materia de 
protección y asistencia a las víctimas de los delito, debido a que tiene que establecer mecanismos efectivos para tutelar la vida, la dignidad, la libertad, la integridad y la seguridad de las personas, así como el libre desarrollo de niñas, niños y adolescentes, cuando sean amenazados o lesionados por la comisión de los delitos y por ultimo reparar el daño a las víctimas de trata de personas de manera integral, adecuada, eficaz y efectiva, proporcional a la gravedad del daño causado y a la afectación sufrida (Cámara de Diputados del H. Congreso de la Unión, (2012).

También está la Ley para prevenir, combatir y sancionar la trata de personas del estado de Quintana Roo.

Esta ley tiene por objeto la prevención, el combate y la sanción de la trata de personas, así como la protección, atención y asistencia a las víctimas de estas conductas, con la finalidad de garantizar el respeto al irrenunciable derecho a la libertad y la dignidad de las víctimas y posibles víctimas, residentes o trasladadas al territorio de Quintana Roo. Esta Ley se aplicará en todo el territorio de Quintana Roo y sus disposiciones son de orden público e interés social.
Comete el delito de trata de personas quien capte, reclute, induzca, procure, facilite, consiga, promueva, mantenga, acoja, favorezca, retenga, transporte, permita, solicite, ofrezca, traslade, entregue o reciba, para sí o para un tercero, a una o más personas, recurriendo a la coacción física o moral, a la privación de libertad, a la seducción, al engaño, al abuso de poder o de una situación de vulnerabilidad o la concesión o recepción de pagos o beneficios, con fines de explotación (Cámara de Diputados del H. XIL Legislatura Constitucional del Estado Libre y Soberano de Quintana Roo, (2010).

\section{DERECHOS HUMANOS DE LAS MUJERES VÍCTIMAS DE LA TRATA DE PERSONAS.}

La mujer tiene derecho a vivir en un mundo libre de violencia. Ningún escenario le favorece debido a la violencia que existe en la sociedad. La violencia es signo de desequilibrio esto se manifiesta con miedo o terror hacia la persona que lo provoca. Esta persona es quien perjudica a la mujer con violencia física; ya sea con golpes con la mano o con cualquier tipo de 
objeto que utilicen para infringirle el daño.

La violencia psicológica es aquel que se realiza verbalmente, esto quiere decir que es afectada por medio de insultos a tal grado de que la mujer se sienta en mal, se deprima y su autoestima sea demeritada. Y la violencia sexual es aquella que obliga a la mujer a tener relaciones sexuales en contra de su voluntad. Estos factores de violencia nos llevan a un contexto de las que la mujer siempre ha sido víctima. Las protecciones legales existentes son las que ayudan para penalizar a los que realizan estos delitos y hacerlos que cumplan con su condena. Ahora bien la trata de personas causa más daño a la mujer porque en este caso se encuentra la violencia física, psicológica y sexual. Las tres son originadas por el delito de trata de persona, es decir todas las mujeres son expuestas a que le causen estos tres factores se crean en cada una de las mujeres de trata de personas. Es por ello que la mujer debe y puede vivir sin violencia, incluso puede coexistir sin miedo a que será golpeada, amenazada o violada sexualmente, por el hecho de que las leyes las protegen sin importar sus estatus social, edad, religión, raza, sexo, entre otras (Instituto Nacional de las Mujeres, (2007).

\section{DERECHOS VIOLENTADOS DE LA MUJER, EN EL DELITO DE TRATA DE PERSONA}

Es señalado que los derechos de las mujeres son violentadas y que se quedan en un estado de vulnerabilidad por el delito de trata de personas. Los derechos humanos son facultades, prerrogativas, intereses y bienes de carácter civil, político, económico, social, cultural, psíquico, personal e íntimo, que posee el ser humano, y que se reconocen instrumentos jurisdiccionales e internacionales.

Los derechos humanos son facultades que nos otorgan las normas jurídicas a todas las personas las cuales son universales, intransferibles, inalienables e imprescriptibles. Es decir que los derechos humanos no los podemos dar o vender a otra persona, de ninguna manera es posible transferirlos. Los derechos humanos son fundamentales en cada persona, esto es porque cuando nuestros derechos son violentados o vulnerados podemos defenderlos con las leyes que nos protegen (Instituto Nacional de las Mujeres, (2007). 


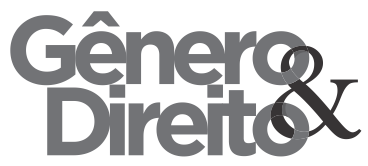

Los derechos más relevantes e

importantes que se encuentran vulnerados

en la trata de personas son:

1.- Derecho de la libertad que se halla en

la Constitución Política de los Estados

Unidos Mexicanos en su artículo 24 y la

define como:

"Toda persona tiene derecho a la libertad de convicciones éticas, de conciencia y de religión, y a tener o adoptar, en su caso, la de su agrado. Esta libertad incluye el derecho de participar, individual o colectivamente, tanto en público como en privado, en las ceremonias, devociones o actos del culto respectivo, siempre que no constituyan un delito o falta penados por la ley. Nadie podrá utilizar los actos públicos de expresión de esta libertad con fines políticos, de proselitismo o de propaganda política" (Cámara de Diputados del H. Congreso de la Unión, (1917).

Este derecho brinda libertad a toda persona dentro de los límites establecidos por la sociedad. Es decir, no se puede ir en contra de la ley porque al realizarlo las autoridades tomaran acción en el caso, por ello, es necesario asimilar
2.- Derecho a la salud que se halla en el artículo $4^{\circ}$ en el párrafo cuarto de la Constitución Política de los Estados Unidos Mexicanos y dice: “... Toda persona tiene derecho a la protección de la salud..." (Cámara de Diputados del H. Congreso de la Unión, (1917).

La Organización Mundial de Salud lo define de la siguiente manera: "...La salud es un estado de completo bienestar físico, mental y social, y no solamente la ausencia de afecciones $\mathrm{O}$ enfermedades...”, “...La desigualdad de los diversos países en lo relativo al fomento de la salud y el control de las enfermedades, sobre todo las transmisibles, constituye un peligro común..." (Asamblea Mundial de la Salud, (2006).

La salud es fundamental para el bienestar de toda persona, por ello se encuentra al margen, desde luego es considerada un derecho individual o colectivo. El estar enfermo es una dificultad para cualquier persona, por ello es indispensable decir que las personas que perjudiquen la salud a una tercera persona 


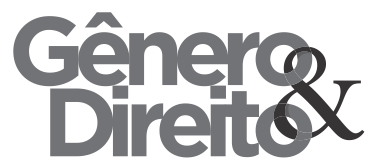

serán sancionadas debido a lo que la ley establece.

3.- Derecho a una vida libre de violencia lo que enfocado hacia la mujer víctima del delito de trata de personas, y referente a la Ley de Acceso a las Mujeres a una Vida Libre de Violencia del Distrito Federal en su artículo $2^{\circ}$ nos dice que:

“... ley es establecer los principios y criterios que, desde la perspectiva de género, orienten las políticas públicas para reconocer, promover, proteger $\mathrm{y}$ garantizar el derecho de las mujeres a una vida libre de violencia; así como establecer la coordinación interinstitucional para prevenir, atender, sancionar y erradicar la violencia contra las mujeres en el marco de los ordenamientos jurídicos aplicables al Distrito Federal y lo previsto en el primero, segundo y tercer párrafos del artículo $1^{\circ}$ de la Constitución Política de los Estados Unidos Mexicanos, respetándose los derechos humanos de las mujeres de conformidad con los principios de universalidad, interdependencia, indivisibilidad, pro persona y progresividad..." (Cámara de Diputados del H. XIL Legislatura Constitucional del
Cedico do Núcleo de Estudos e Pesquisas sobre Gênero e Direito Centro de Ciências Jurídicas - Universidade Federal da Paraíba V. 6 - No 03 - Ano 2017 (Spanish Edition) 136

Estado Libre y Soberano de Quintana Roo, (2010).

Todas las personas tienen el derecho a tener una vida libre de violencia, pero hay que reiterar que las mujeres son las más vulnerables, y que sufren además el delito de trata de personas. Dado a la problemática que coexiste en este delito, la legislación se encarga de prevenirla estableciendo políticas y legislaciones que protejan a los grupos vulnerables.

4.- El Derecho a un ambiente sano también se protege en la legislación anterior, pues el medio en donde interactúa debe servir para ayudar, motivar y empoderar a que la mujer desarrolle su proyecto de vida, al igual que en la Constitución Política de los Estados Unidos Mexicanos en su artículo 4 párrafo quinto que lo define como: “...Toda persona tiene derecho a un medio ambiente sano para su desarrollo y bienestar..." (Cámara de Diputados del H. Congreso de la Unión, (1917).

Es determinante que todas las personas vivan en un ambiente sano y digno esto es por el hecho del ser humano y su facultad para tener una buena satisfacción en su entorno en el que vive. 


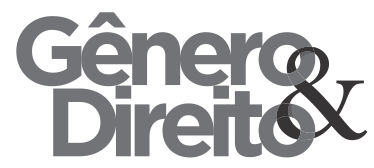

5.- Derecho a la igualdad de género establecido en la Constitución Política de los Estados Unidos Mexicanos en su artículo $4^{\circ}$ que dice: “...El varón y la mujer son iguales ante la ley..." Lo que se entiende como una realidad en la que muchos no están de acuerdo, y que implica que las mujeres tendrán las mismas oportunidades que los hombres (Cámara de Diputados del H. Congreso de la Unión, (1917).

Desafortunadamente a las mujeres les han cerrado la puerta a oportunidades a las que tienen derechos. Las mujeres de trata de personas son privadas de la libertad por personas que no las respetan, sin importarles esa igualdad y el derecho de hombres y mujeres a ser tratados de acuerdo a una forma digna.

CONSECUENCIAS DE LA TRATA DE PERSONAS EN LAS MUJERES QUE SON VÍCTIMAS DE ESTE DELITO.

La trata de personas es una grave violación a los derechos humanos y la dignidad de las mujeres. Los malos tratos dico do Núcleo de Estudos e Pesquisas sobre Gênero e Direito Centro de Ciências Jurídicas - Universidade Federal da Paraíba V. 6 - No 03 - Ano 2017 (Spanish Edition)

y la coacción y la frecuencia de la violencia física infringida deja secuelas en el cuerpo de la víctima, también al ser expuestas a la explotación sexual existe la posibilidad de que sufra de contagio de enfermedades de transmisión sexual, como la trasmisión del VIH/SIDA, de sufrir abortos causados por la violencia y maltratos, incluso pueden causar la muerte de las víctimas de este delito.

Las víctimas posteriormente de ser salvadas son rechazadas en la sociedad, que no sabe cómo tratarlas y relacionarse con ellas después de los abusos que les causaron. La violencia psicológica además de volverlas inseguras de sí misma, las hacen perder la autoestima debido a los traumas que le provocaron por los golpes y amenazas y el ambiente de peligro en que sobrevivieron (Organización Internacional para las Migraciones [OIM], (2006).

\section{PROPUESTAS:}

1.- Que las autoridades puedan desplazarse a los lugares de poca vigilancia para poder evitar que capturen o secuestren a las mujeres que por desconocimiento $\mathrm{y}$ protección son vulnerables. 


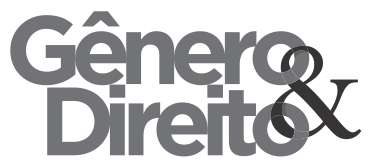

2.- Que la sociedad ayude y apoye con llamadas anónimas en teléfonos públicos o privados, cuidando de dicha privacidad.

3.- Continuar en la procura de enseñanza y capacitación para que los hombres acepten a las mujeres con la misma equidad en que ellos son tratados, sin hacer discriminación y tampoco tratarlas de manera inferior a ellos.

4.- Que las leyes nacionales e internacionales se cumplan erradicando la corrupción que existe en el sistema jurídico mexicano.

5.- Que las mujeres sean alertadas por medios de comunicación como la televisión, radio, periódicos, los medios de protección y prevención, también educar y prevenir el delito por medio de pláticas a comunidades rurales e indígenas que no cuentan con la información suficiente.

\section{CONCLUSIONES}

La trata de personas es un delito mundial, el cual afecta a la población y minimiza a las mujeres al considerarlas un objeto sexual, humillando y violando su esencia como mujer. La dignidad y voluntad de las mujeres es destruida con el objetivo de obligarlas a cumplir los deseos dico do Núcleo de Estudos e Pesquisas sobre Gênero e Direito Centro de Ciências Jurídicas - Universidade Federal da Paraíba V. 6 - No 03 - Ano 2017 (Spanish Edition)

y voluntad de los agresores. Toda persona tiene derecho a ser respetada en su persona establecido en las leyes Nacionales e Internacionales, y buscan proteger a la mujer de delitos como trata de personas y violencia física, psicológica y sexual y todo aquello que dañe o perjudique a la mujer. También es por ello que debemos de ayudar a evitar este delito recurriendo a las autoridades para que realicen investigaciones y puedan rescatar a las mujeres lo más pronto posible para evitarles la tortura y violencia a que se ven sometidas.

Por ser un delito que no respeta límites territoriales, tanto los países como las organizaciones internacionales se han preocupado de establecer leyes e instrumentos para dar forma a un marco jurídico lo suficientemente fuerte que logre erradicar y prevenir este tipo de delito, aunque lucha constantemente contra la impunidad existente en la sociedad.

Las autoridades son parte fundamental para defender a las mujeres de dichos delitos que denigran a la mujer. De eso deriva todo para hacer la disminución del delito y tener la certeza 


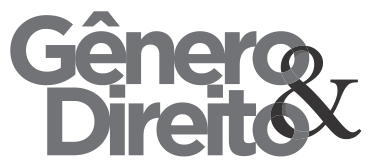

de que se va contrarrestar y tener la justicia que muchas mujeres necesitan.

\section{REFERENCIA BIBLIOGRÁFICA}

Asamblea Legislativa del Distrito Federal, VII Legislatura, (2008). Ley de Acceso de las Mujeres a una vida libre de Violencia del Distrito Federal. Reforma Gaceta Oficial del Distrito Federal 2015. Ciudad de México. Recuperado en http://www.aldf.gob.mx/archivofde12a5698a6daa612f4515f386b1beb.pdf

Asamblea Mundial de la Salud, (2006). Constitución de la Organización Mundial de la

Salud. Recuperado en http://www.who.int/governance/eb/who_c onstitution_sp.pdf

Cámara de Diputados del H. Congreso de la Unión, (1917). Constitución Política de los Estados Unidos Mexicanos. Reforma publicada DOF 24-02-2017. Diario Oficial de la Federación. Recuperado en http://www.diputados.gob.mx/LeyesBibli o/pdf/1_240217.pdf
Cenco do Núcleo de Estudos e Pesquisas sobre Gênero e Direito Centro de Ciências Jurídicas - Universidade Federal da Paraíba V. 6 - No 03 - Ano 2017 (Spanish Edition) , (1988).

Ley General del Equilibrio Ecológico y la Protección al Ambiente. Reforma en el DOF 24-01-2017. Diario Oficial de la Federación. Recuperado en http://www.diputados.gob.mx/LeyesBibli o/pdf/148_240117.pdf , (2012). Ley General para prevenir, sancionar y erradicar los delitos en materia de Trata de Personas y para la Protección y Asistencia a las víctimas de estos delitos. Diario Oficial de la Federación. Reforma publicada DOF 1903-2014. Recuperado en http://www.diputados.gob.mx/LeyesBibli o/pdf/LGPSEDMTP.pdf

Cámara de Diputados del H. XIL Legislatura Constitucional del Estado Libre y Soberano de Quintana Roo, (2010). Ley para Prevenir, Combatir y Sancionar la Trata de Personas del Estado de Quintana Roo. Número Extraordinario del Periódico Oficial del Estado de Quintana Roo. Recuperado en http://www.inegi.org.mx/est/contenidos/p $\underline{\text { royectos/aspectosmetodologicos/clasifica }}$ 


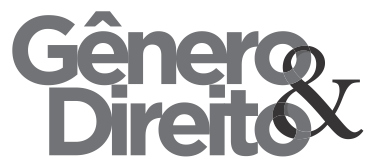

doresycatalogos/doc/estatal/LltdpdQuinta

$\underline{\text { naRoo.pdf }}$

Comisión Nacional de los Derechos

Humanos [CNDH], (2012). La Trata de

Personas. Impreso en México. Primera

Edición.

Recuperado

en

http://www.cndh.org.mx/sites/all/doc/cart

illas/8_Cartilla_Trata.pdf

Fondo de las Naciones Unidas para la

Infancia [UNICEF], (2007). Trata de

Personas, especialmente mujeres y niñas.

Una forma de esclavitud moderna.

Ministerio de Justicia, Seguridad y

Derechos Humanos. Primera Edición.

Argentina. Recuperado en

https://www.unicef.org/argentina/spanish/

$\underline{\text { OriginalTrataPersonas.pdf }}$

Instituto Nacional de las Mujeres, (2007).

Derechos de las Mujeres. Tercera Edición.

ISBN: 978-968-5552-95-0. México.

Recuperado en

http://www.sct.gob.mx/fileadmin/_migrat

ed/content_uploads/Derechos_Humanos_

$\underline{\text { de_las_Mujeres.pdf }}$

Ivelissec2, (2014). Análisis a la Ley 137-

03 sobre Trata Tráfico de Inmigrantes.
Cen do Núcleo de Estudos e Pesquisas sobre Gênero e Direito Centro de Ciências Jurídicas - Universidade Federal da Paraíba V. 6 - No 03 - Ano 2017 (Spanish Edition) 140
ClubEnsayos.
Temas
Variados.

Recuperado

en

https://www.clubensayos.com/Temas-

$\underline{\text { Variados/ANALISIS-A-LA-LEY-137- }}$

03-SOBRE-TRATA-

$\underline{\text { TRAFICO/1666410.html }}$

Naciones Unidas [ONU], (1999).

Protocolo Contra el Tráfico Ilícito de Migrantes por Tierra, Mar y Aire.

Recuperado

en

http://www.oas.org/juridico/spanish/trata

dos/sp_proto_cont_tr\%C3\%A1fi_1\%C3\%

ADci_migra_tierra_mar_aire_comple_co

$\underline{\text { nve_nu_cont_delin_orga_transn.pdf }}$

Oficina de las Naciones Unidas contra la Droga y el Delito [UNODC], (2009). Tráfico ilícito de migrantes. Austria. Recuperado en

https://www.unodc.org/documents/human -trafficking/Migrant_Smuggling/09-

81209_Spanish_ebook.pdf

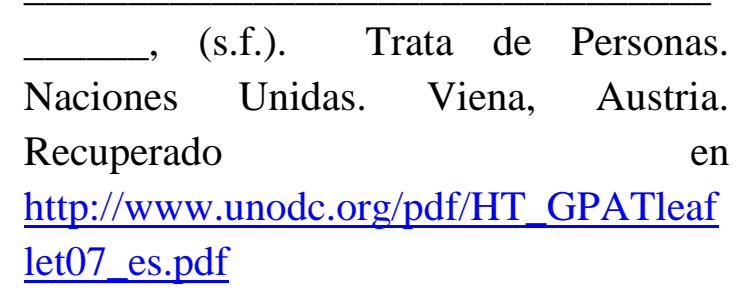




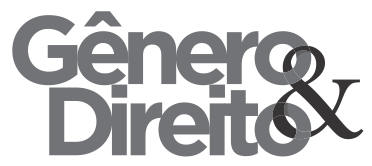

Organización de los Estados Americanos

[OEA], (1969). Convención Americana sobre Derechos Humanos (Pacto de San José). Recuperado en https://www.oas.org/dil/esp/tratados_b32_convencion_americana_sobre_derech os_humanos.htm

_, (1994). Convención Interamericana para prevenir, sancionar y erradicar la Violencia contra la Mujer "Convención de Belem Do Para". Belem do Pará, Brasil. Recuperado en http://www.oas.org/juridico/spanish/trata dos/a-61.html

Organización Internacional para las Migraciones [OIM], (2006). La Trata de Personas, Aspectos Básicos. Primera

Edición. México. Recuperado en https://www.oas.org/atip/reports/trata.asp ectos.basicos.pdf

Tirzo, (2014). Ocupa Puebla segundo lugar en Trata de Personas. Milenio.com. Estados. Obtenido de http://www.milenio.com/estados/tratatrata_de_personas-
Puebla_seg
$\underline{9511 . h t m l}$

segundo_lugar_de_trata_0_40675

V. 6 - No 03 - Ano 2017 (Spanish Edition) Centro de Ciências Jurídicas - Universidade Federal da Paraíba

/periodicos.ufpb.br/ojs2/index.php/ged/index 